\title{
Synthesis and Characterization of Composite Polypyrrole-Vanadium Oxide $\left(\mathrm{PPy} / \mathrm{V}_{2} \mathrm{O}_{5}\right)$
}

\author{
Nurhizwati Abd. Rahman ${ }^{1}$, Tunku Ishak Tunku Kudin ${ }^{1}$, Ab. Malik Marwan Ali ${ }^{1,2}$ and Muhd Zu Azhan Yahya ${ }^{1,2}$ \\ 1. Ionics Materials \& Devices (iMADE) Research Laboratory, Faculty of Applied Sciences, Universiti Teknologi MARA, 40450 Shah \\ Alam, Malaysia
}

2. Institute of Science, Universiti Teknologi MARA, Shah Alam 40450, Malaysia

Received: April 30, 2011 / Accepted: May 18, 2011 / Published: September 25, 2011

\begin{abstract}
Conducting polymer attracts broad attention to researchers due to their good properties such as high environmental friendly, thermal and chemical stability as well as high conductivity. There are widely use in potential components of optical storage, sensors, batteries, supercapacitor and so on. In this work, polypyrrole was synthesized using chemical oxidation polymerization technique which involves $\mathrm{FeCl}_{3}$ and nanoparticle vanadium oxide $\left(\mathrm{V}_{2} \mathrm{O}_{5}\right)$. The composite $\mathrm{PPy} / \mathrm{V}_{2} \mathrm{O}_{5}$ has been synthesized under $0{ }^{\circ} \mathrm{C}$ with variation weight percentage of nanoparticle $\mathrm{V}_{2} \mathrm{O}_{5}$ from $10 \%$ to $50 \%$ with increment of $10 \%$. The properties of composites have been characterized by x-ray diffraction (XRD) and Field Scanning Electron Microscopy (FESEM). The ac conductivity has been carried out under frequency range of $100 \mathrm{~Hz}$ to $1 \mathrm{MHz}$ over temperature $273 \mathrm{~K}$ to $393 \mathrm{~K}$. It is observed that the ac conductivity of composite increass steeply after frequency of $105 \mathrm{~Hz}$. The composite $P P y-\mathrm{V}_{2} \mathrm{O}_{5}$ has shown the larger $d$-spacing compared to pure PPy and FESEM shows the spongy-like graph of pure polypyrrole than composite $\mathrm{PPy} / \mathrm{V}_{2} \mathrm{O}_{5}$.
\end{abstract}

Key words: Polypyrrole, $\mathrm{V}_{2} \mathrm{O}_{5}$, composite, chemical polymerization.

\section{Introduction}

Polymers have emerged as one of the most important materials in the twentieth century. It does contain a long chain of molecular structure and categorized as insulators. The discovery in 1977 of the high conductivity of doped acetylene stimulated studies on the synthesis and study of various conjugated polymers. The most popular conjugated conducting polymers are polyaniline [1], polythiophene [2] and polypyrrole [3]. Polypyrrole have attracted much interest worldwide due to its easy preparation, environmentally stable and has high electrical conductivity [4]. Scientist have discover around many years ago about the ability of conjugated polymer called polyacetylene [5] to conducts electrically after undergoing a structural modification process called doping [6]. The electrical

Corresponding author: Muhd $\mathrm{Zu}$ Azhan Yahya, professor, research field: conducting polymer. E-mail: mzay@salam.uitm.edu.my. conductivity of these polymers is between $10^{-5} \mathrm{~S} / \mathrm{cm}$ and $10^{2} \mathrm{~S} / \mathrm{cm}$ while doped, whereas common insulators exhibit conductivities below $10^{-12} \mathrm{~S} / \mathrm{cm}$ [7]. The potential applications of this conducting polymers or organic metals include sensors [8], batteries [9], corrosion protection [10], as well as supercapacitors due to high doping level and fast electrochemical switching with significant capacitance values [11]. Composite of polypyrrole with various nanoparticles have been studied. Nanocomposite polypyrrole $/ \mathrm{V}_{2} \mathrm{O}_{5}$ in applications of $\mathrm{Li}$ ion battery [12], polypyrrole/iron oxide in applications of sensors and. Several other small particles have been incorporated in to polypyrrole such as silica [13], and titanium dioxide [14].

\section{Experiment}

Composite $\mathrm{PPy} / \mathrm{V}_{2} \mathrm{O}_{5}$ has been synthesized using chemical oxidation polymerization method. Pyrrole 
(Aldrich, 98\%) was distilled before used. Ferric chloride (Sigma-Aldrich, 97\%) as an oxidant was dissolve in $1 \mathrm{M}$ hydrochloric acid $(\mathrm{HCl})$ together with vanadium oxide (Sigma-Aldrich, 99.99) and stirred under temperature $0{ }^{\circ} \mathrm{C}-5{ }^{\circ} \mathrm{C}$. the weight percentage of $\mathrm{V}_{2} \mathrm{O}_{5}$ was varied from $10 \%$ to $50 \%$ with increment every $10 \%$. After stirring for $30 \mathrm{~min}$, the pyrrole monomer was injected into the mixture to form composite $\mathrm{PPy} / \mathrm{V}_{2} \mathrm{O}_{5}$. The final product was filtered and rinsed thoroughly with methanol $\left(\mathrm{CH}_{3} \mathrm{OH}\right)$ and acetone $\left[\left(\mathrm{CH}_{3}\right)_{2} \mathrm{CO}\right]$ to remove the excess solvents. Finally, the precipitate was dried in vacuum oven at $60^{\circ} \mathrm{C}$ for more than $12 \mathrm{~h}$. Then, composite powders are ready to be characterized.

The composite powder are pressed into round pallet with diameter of $1.53 \mathrm{~cm}$ and thickness in range of 0.81 $\mathrm{mm}$ to $1.34 \mathrm{~mm}$ using hydraulic pressure by applying the pressure of 2-3 tonnes. The ac conductivity was measured in the frequency of $100 \mathrm{~Hz}$ to $1 \mathrm{MHz}$ using HIOKI 3532-50 LCR Hi-Tester over temperature of $273 \mathrm{~K}$ to $393 \mathrm{~K}$. The $\mathrm{x}$-ray pattern of the composites were recorded in Xpert Pro Pan Analytical using $\mathrm{Cu} \mathrm{K} \alpha$ radiation $(\lambda=1.5406 \AA)$ at $45 \mathrm{kV}$ and $20 \mathrm{~mA}$ in the range of $5-90^{\circ}$. The morphology images of composite polypyrrole-vanadium oxide were recorded by FEI Quanta FEG $200 \mathrm{~F}$ field emission scanning electron microscope (FESEM).

\section{Results and Discussions}

Fig. 1 depicts the room temperature conductivity plots of composite polypyrrole with various vanadium oxide contents at $100 \mathrm{kHz}$. The addition of nanoparticle vanadium oxide results in decrease in conductivity up to $10 \%$ vanadium oxide in polypyrrole. A low value plateau formed and thereafter remains constant starting from the $20 \%$ to $50 \%$ addition of vanadium oxide.

A different ac conductivity of pure polypyrrole and composite polypyrrole-vanadium oxide are shown in Fig. 2. It can be seen that the ac conductivity of pure polypyrrole increases constantly while the ac conductivity of composite polypyrrole-vanadium oxide

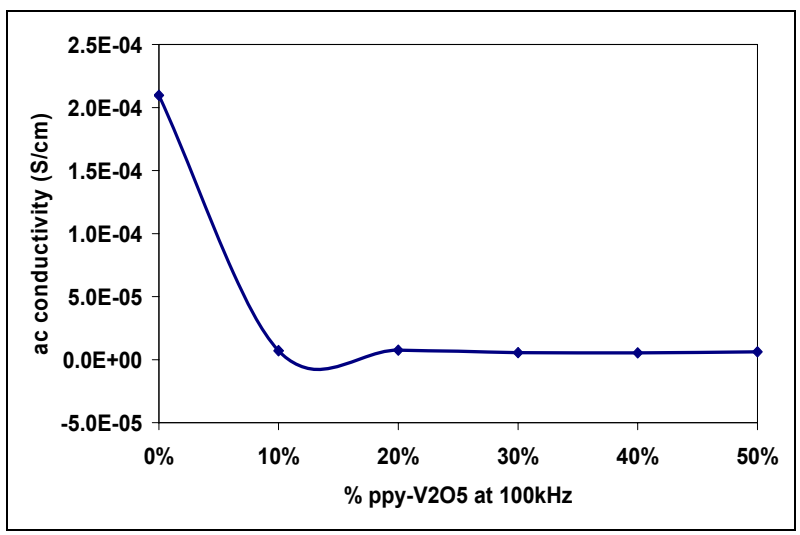

Fig. 1 Ac conductivity of composite in PPy and composite $\mathbf{P P y} / \mathrm{V}_{2} \mathbf{O}_{5}$.

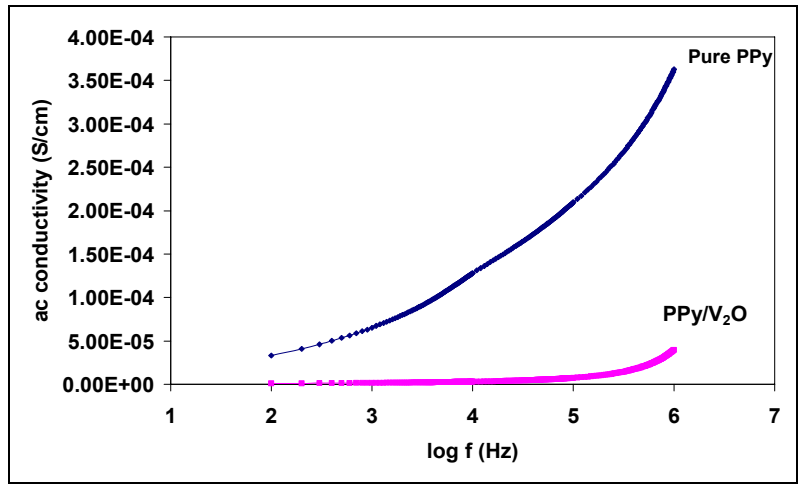

Fig. 2 Ac conductivity versus frequency for pure variation of $\mathrm{V}_{2} \mathrm{O}_{5}$ weight percentage.

remains constant until frequency of $10^{5} \mathrm{~Hz}$ and increases steeply thereafter.

Fig. 3 shows an ac conductivity of composite polypyrrole-vanadium oxide in frequency range $10^{2} \mathrm{~Hz}$ to $10^{6} \mathrm{~Hz}$. From the graph, it can be seen that all composite polypyrrole-vanadium oxide which from $10 \%$ to $50 \%$ weight percentage of vanadium oxide shows the increase in ac conductivity steeply starting from frequency of $10^{5} \mathrm{~Hz}$ which represent the characteristic feature of disorder material. It can be said that the increase of ac conductivity at higher frequency is due to the contribution of polarons. The smaller distance in polymeric chain directed the polaron to move easily. In addition, the movement of the charge in amorphous region also happens at higher frequency.

From the XRD pattern in Fig. 4, the sharp peak was observed at $2 \theta=14.8^{\circ}$ for Fig. $4 \mathrm{~b}$ and broad peak at $2 \theta=26.8^{\circ}$ in Fig. $4 \mathrm{a}$. The peak suggesting the phase of the composite is more to crystalline compared to 
amorphous phase in pure polypyrrole. By applying Bragg's equation, the $d$-spacing or interlayer spacing can be determined. The $d$-spacing of pure polypyrrole and composite $\mathrm{PPy}-\mathrm{V}_{2} \mathrm{O}_{5}$ is 3.32 and 5.96 respectively. The larger $d$-spacing would result in lower conductivity where there is a difficulty of electron to hop from one layer to another. These results are in agreement conductivity in Fig. 1.

Fig. 5 shows scanning electron micrograph of pure polypyrrole while Fig. 6 shows micrograph of composite polypyrrole-vanadium oxide at vanadium oxide weight percent of $20 \%$ in polypyrrole. It can be seen that the degree of surface density of composite $\mathrm{PPy}-\mathrm{V}_{2} \mathrm{O}_{5}$ has a much denser structure compared to pure PPy which can be said that the pure polypyrrole is spongier than composite $\mathrm{PPy} / \mathrm{V}_{2} \mathrm{O}_{5}$. The spongy

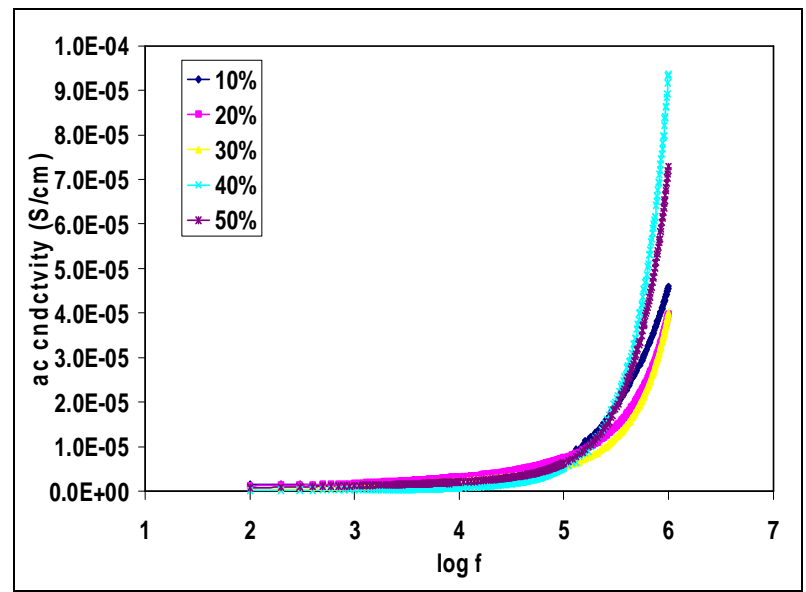

Fig. 3 Ac conductivity versus frequency for composite $\mathrm{PPy} / \mathrm{V}_{2} \mathrm{O}$.

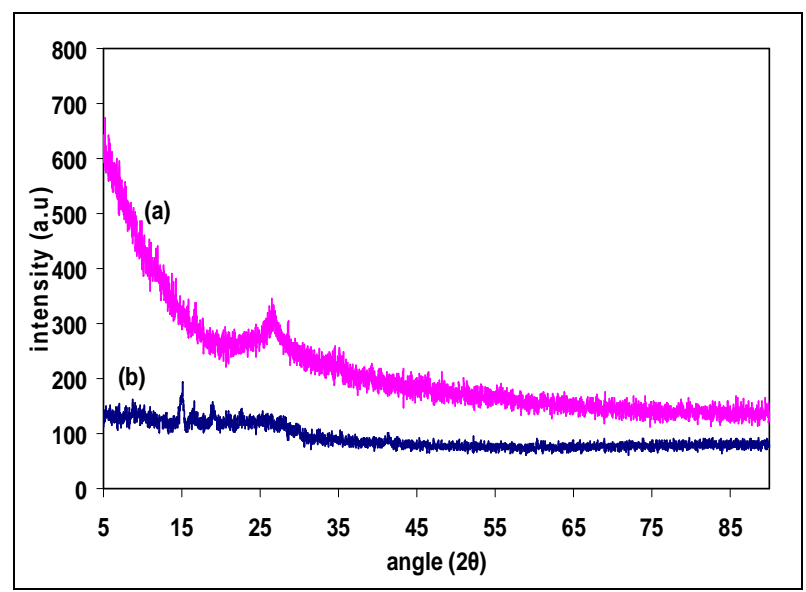

Fig. 4 X-ray spectroscopy of (a) pure PPy (b) composite $\mathrm{PPy} / \mathrm{V}_{2} \mathrm{O}_{5}\left(20\right.$ wt $\%$ of $\left.\mathrm{V}_{2} \mathrm{O}_{5}\right)$.

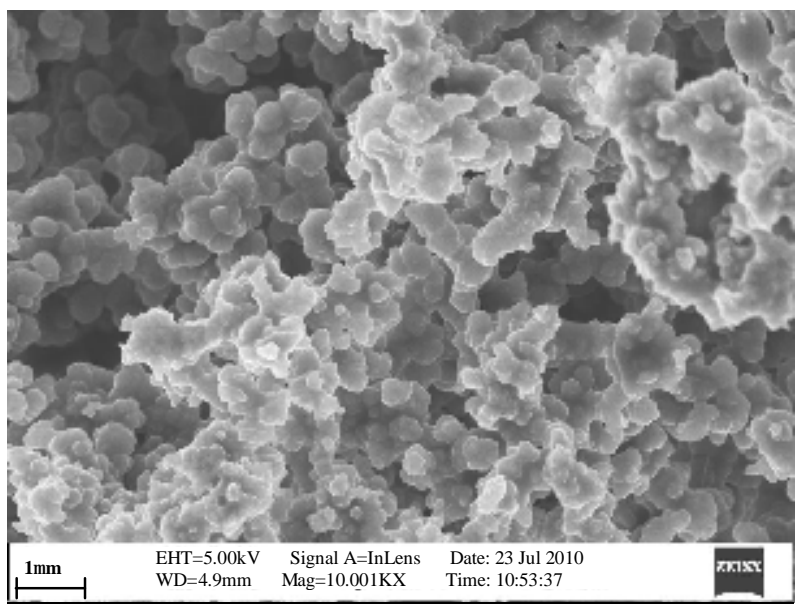

Fig. 5 Scanning electron micrograph of polypyrrole.

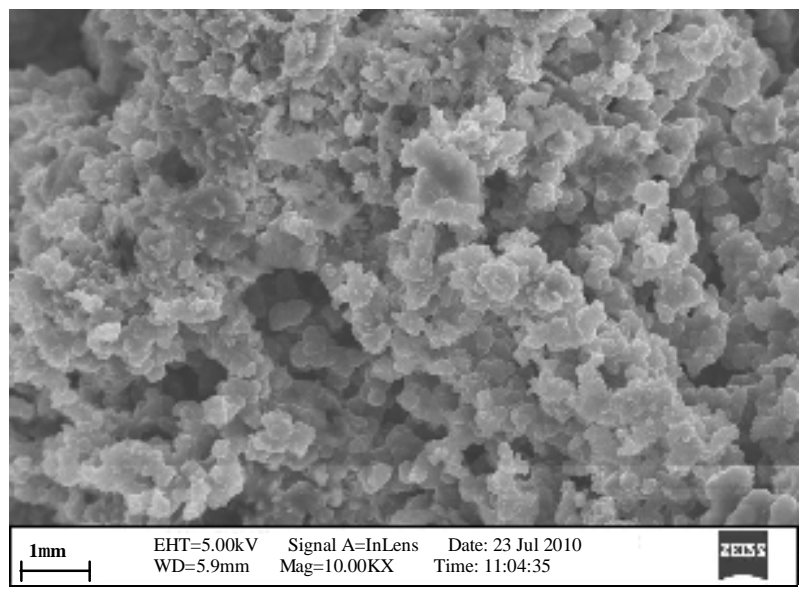

Fig. 6 Scanning electron micrograph of composite $\mathrm{PPy}-\mathrm{V}_{2} \mathrm{O}_{5}$ at 20 wt. \% of $\mathrm{V}_{2} \mathrm{O}_{5}$.

feature in pure polypyrrole shows that the more amorphous of the structure. This result is in-line with the result of ac conductivity where the increase in conductivity is due to the amorphousity of the sample.

\section{Conclusions}

The syntheses have been made and their characteristics are collected. The results in conductivity are in-line with the result of FESEM and XRD. The denser structure was found in composite $\mathrm{PPy}-\mathrm{V}_{2} \mathrm{O}_{5}$ while the spongy-like structure was observed at pure PPy. The addition of $\mathrm{V}_{2} \mathrm{O}_{5}$ in polypyrrole shows the changing of phase which is from amorphous to more crystalline phase. The sample of composite $\mathrm{PPy}-\mathrm{V}_{2} \mathrm{O}_{5}$ has shown the larger $d$-spacing than pure polypyrrole which result the 
lower conductivity. It can conclude that the amorphousity of the samples will affect its conductivity.

\section{Acknowledgment}

The author would like to express the great gratitude to Ministry of Science, Technology and Innovation Malaysia for the PGD scholarship awarded and Ministry of Higher Education for supported in Fundamental Research Grant Scheme [grant no. 600-RMI/ST/FRGS 5/3/Fst (21/2009).

\section{References}

[1] S. Bhadra, D. Khastgir, N.K. Singha, J.H. Lee, Progress in preparation, processing and applications of polyaniline, Progress in Polymer Science 34 (2009) 783-810.

[2] S. Osawa, T. Ogawa, M. Ito, Molecular orientation of electrochemically synthesized polythiophene: effects of temperature, solvent and magnetic field, Synthetic Metals. 90 (1997) 81-88.

[3] S. Barnoss, H. Shanak, C.C. Bufon, T. Heinzel, Piezoresistance in chemically synthesized polypyrrole thin films, Sensors and Actuators A: Physical 154 (2009) 79-84.

[4] K.K. Kanazawa, A.F. Diaz, R.H. Geiss, W.D. Gill, J.F. Kwak, J.A. Logain, et al., 'Organic metals': polypyrrole, a stable synthetic 'metallic' polymer, J. Chem. Soc. Chem. Comm. 19 (1979) 854.

[5] Z. Skanderi, A. Djebaili, Y. Bouzaher, M. Belloum, M.J.M. Abadie, Impact of synthesis conditions on electrical conductivity of oriented and doped polyacetylene, Composites Part A: Applied Science and Manufacturing 36 (4) (2005) 497-501.

[6] D. Bormann, J.L. Sauvajol, M. Armand, R. Aznar, P.
Bernier, A new type of p-doping for polyacetylene, Synthetic Metals 69 (1995) 2122.

[7] B. Kim, V. Koncar, E. Devaux, Electrical properties of conductive polymers: PET-nanocomposites' fibres, AUTEX Research Journal 4 (1) (2004) 9-13.

[8] T. Zhang, Y. He, R. Wang, W.C. Geng, L.J. Wang, L.G. Niu, et al., Analysis of DC and AC properties of humidity sensor based on polypyrrole materials, Sensors and Actuators B: Chemical 131 (2) (2008) 687-691.

[9] B.N. Grgur, M.M. Gvozdenović, J. Stevanović, B.Z. Jugović, V.M. Marinović, Polypyrrole as possible electrode materials for the aqueous-based rechargeable zinc batteries, Electrochimica Acta 53 (14) (2008) 4627-4632.

[10] E. Armelin, R. Pla, F. Liesa, X. Ramis, J.I. Iribarren, C. Alemán, Corrosion protection with polyaniline and polypyrrole as anticorrosive additives for epoxy paint, Corrosion Science 50 (3) (2008) 721-728.

[11] R.K. Sharma, A.C. Rastogi, S.B. Desu, Pulse polymerized polypyrrole electrodes for high energy density electrochemical supercapacitor. Electrochemistry Communications 10 (2) (2008) 268-272.

[12] F. Huguenin, E.M. Girotto, R.M. Torresi, D.A. Buttry, Transport properties of $\mathrm{V}_{2} \mathrm{O}_{5}$ /polypyrrole nanocomposites prepared by a sol-gel alkoxide route, Journal of Electroanalytical Chemistry 536 (2002) $37-45$.

[13] C. Perruchot, M.M. Chehimi, M. Delamar, F. Dardoize, SIMS analysis of conducting polypyrrole-silica gel composites, Synthetic Metal 113 (2000) 53-63.

[14] H. Yuvaraj, E.J. Park, Y.S. Gal, K.T. Lim, Synthesis and characterization of polypyrrole- $\mathrm{TiO}_{2}$ nanocomposites in supercritical $\mathrm{CO}_{2}$, Colloids and Surfaces A: Physicochemical and Engineering Aspects 313-314 (2008) 300-303. 